\title{
ENSINO DE MEDICINA LEGAL E PERÍCIAS MÉDICAS FUNDAMENTADO EM COMPETÊNCIAS: UMA NOVA PROPOSTA CURRICULAR
}

\author{
Diogo Nilo Miranda Borba ${ }^{1}$ e Francisco José Passos Soares ${ }^{2}$ \\ Universidade Federal de Alagoas, Brasil, 'diogo_nilo@hotmail.com; 2francisco_passos01@hotmail.com
}

\begin{abstract}
Resumo. Em 2011 foi reconhecida uma nova especialidade médica: Medicina Legal e Perícias Médicas (MLPM). Em 2014 foi publicada a resolução que regulamenta as Novas Diretrizes Curriculares Nacionais do Curso de Graduação em Medicina baseadas em competências, e não há clareza na adequação da disciplina de medicina legal e perícias médicas para o novo modelo do currículo médico. O presente estudo pretendeu contribuir para a reflexão dos gestores, professores e alunos sobre os limites da MLPM no currículo médico atual. Para estudar e propor a atualização das competências em MLPM para um curso público de medicina foi utilizado o método Delphi, em duas rodadas, através da consulta de especialistas na área, em busca do consenso acerca da matriz de competências específica. Como resultado obteve-se uma sugestão de matriz curricular ainda conservadora, porém com alguns avanços na inclusão de temas relevantes no campo pericial, que se aproximam da atuação médica social, do protagonismo do aluno no aprendizado e de um currículo integrador. Uma matriz curricular inovadora no campo pericial contribui para a humanização da formação médica.
\end{abstract}

Palavras-chave: Medicina Legal; Medicina; Educação Baseada em Competência; Técnica Delfos; Educação Médica.

\section{TEACHING OF FORENSIC MEDICINE AND MEDICAL EXPERTISE BASED ON SKILLS: A NEW CURRICULUM PROPOSAL}

\begin{abstract}
A new medical specialty was recognized in 2011: Forensic Medicine and Medical Expertise (FMME). In 2014 a skill-based resolution that regulates the New National Curriculum Guidelines to Undergraduate Medicine Course was published, and there's no clarity on the Forensic Medicine and Medical Expertises subject adequacy to the new model of the medical curriculum. This work intended to contribute with managers, teachers and, pupils about FMME limits on the current medical curriculum. To study and propose an update on FMME skills to a public Medicine course, the Delphi method was applied in two turns, through the consult experts of this field, searching for a consensus over the specific skills matrix. A suggestion of a yet conservative matrix was obtained as result, but with few advances in the inclusion of relevant themes in the forensic field, that approximates the social medical acting, to the pupil's protagonism on the learning process and an integrative curriculum. An innovative curricular matrix in the forensic field contributes to the humanization of medical education.
\end{abstract}

Keywords: Forensic Medicine; Medicine. Skill-based Education; Delphi technique; Medical Education.

\section{INTRODUÇÃO}

Os conflitos sociais são inerentes à condição humana. O homem sempre buscou o Estado, por meio do poder judiciário, para ver seus direitos assegurados. A Constituição Federal (1988), em seu Título II, remete aos direitos e garantias fundamentais, que correspondem ao conjunto de direitos mínimos para que o sujeito possa viver dignamente, não podendo ser atingidos por nenhum outro cidadão e nem restringidos pelo próprio Estado. As ciências precisam estar atentas às mudanças de comportamento social a fim de que se ponham as 
adequações necessárias e de tentar dar à pessoa a possibilidade de viver de forma digna. Atualmente o direito está em evidência na concretização da sua função de pacificação social, carecendo do auxílio das demais ciências. A Medicina, que busca a saúde integral, encontrou na Medicina Legal e Perícias Médicas (MLPM) uma forma de auxiliar nas relações intersubjetivas.

A perícia médico-legal é um conjunto de procedimentos médicos e técnicos que tem como finalidade o esclarecimento de um fato de interesse da justiça através da produção da prova, que se materializa por meio do laudo (França, 2015).

São evidentes a transformação e os avanços nos cursos de Medicina no Brasil nos últimos anos. As atuais Diretrizes Curriculares Nacionais do Curso de Graduação em Medicina, expressas na Resolução n ${ }^{\circ} 3$ (2014) do Conselho Nacional de Educação (CNE), sinalizam a necessidade e a importância da mudança na organização curricular nas instituições de ensino superior no Brasil, direcionando os currículos para o desenvolvimento de competências profissionais.

Um currículo baseado em competências busca formar o profissional com foco no desenvolvimento de conhecimentos, habilidades e atitudes suficientes para identificar, enfrentar e solucionar os desafios inerentes ao cotidiano (Gontijo, Alvim, Megale, Melo, \& Lima, 2013).

Em $1^{\circ}$ de abril de 2011, as Sociedades Brasileiras de Medicina Legal e de Perícias Médicas fundiram-se na constituição da Sociedade Brasileira de Medicina Legal e Perícias Médicas (ABMLPM). Em agosto do mesmo ano foi publicada a Resolução n 1.973 (2011) do Conselho Federal de Medicina, que oficializa o reconhecimento da especialidade. Essa resolução é o marco inicial da consolidação da representatividade na participação efetiva do médico no âmbito pericial, quer seja nas áreas penal, judicial civil, trabalhista, administrativa, securitária ou previdenciária.

Embora a Medicina Legal seja obrigatória e consolidada na matriz curricular, a Medicina Pericial ainda aparece de forma incipiente na formação acadêmica, apesar de ocupar espaço considerável como área de atuação e na pós-graduação do médico. Torna-se imprescindível, portanto, adequar o currículo médico, atualizando-o ante às competências em medicina pericial. 
Este artigo teve como objetivo a elaboração de uma matriz de competências em medicina legal inclusiva do campo médico pericial.

\section{MÉTODOS}

Estudo de caso exploratório, de natureza qualitativa, realizado no período de abril a outubro de 2019. A amostra populacional inicial foi constituída por vinte docentes e preceptores médicos atuantes em Medicina Legal e Perícias Médicas, bem como médicos membros do Conselho Regional de Medicina de Alagoas. A técnica de seleção amostral foi a "bola de neve" (Scarparo, Laus, Lidia, Gabriel, Dias, \& Chaves, 2012; Biernacki \& Waldorf, 1981), na qual os participantes indicam outros que correspondem aos critérios da pesquisa.

Para a definição das competências em MLPM necessárias para a formação generalista, foi utilizado o método Delphi. Esse método é definido como um processo efetivo de estruturação da comunicação grupal que permite a discussão de problemas complexos (Villiers, Villier \& Kent, 2005). É uma ferramenta de pesquisa qualitativa que sistematiza o julgamento de informações. Consiste na aquisição de consenso entre os peritos da área objeto do estudo por meio de validações em fases ou ciclos (Scarparo et al., 2012). Para que se dê tal estruturação, o processo deve oferecer algumas condições básicas: o anonimato entre os participantes; a consulta de especialistas para coleta dos dados; uma análise dos resultados com feedback das contribuições individuais a cada rodada; e a busca pelo consenso (Sáfadi, 2001).

No presente caso, o uso do método Delphi foi justificado pelos seguintes motivos: impossibilidade de reunir os especialistas participantes; a facilidade da coleta de dados pela internet; e a adequação do método ao objetivo pretendido.

Optou-se pela utilização de um formulário eletrônico (via Formulários Google) previamente elaborado para esta finalidade, acompanhado do Termo de Consentimento Livre Esclarecido (TCLE), o qual foi aplicado aos participantes, em duas rodadas, por meio de correio eletrônico e aplicativo de mensagens (WhatsApp), buscando a uniformização de opiniões.

A primeira rodada do questionário eletrônico baseou-se na caracterização da amostra e de perguntas suficientes para a enumeração pelos participantes de todas as competências julgadas necessárias à formação do clínico, resultando num rol de competências em Medicina Legal e Perícias Médicas. 
O questionário enviado a vinte especialistas foi respondido por apenas doze, tendo a seguinte estrutura:

Parte I - Caracterização da amostra: nome; idade; tempo de formado; especialidade; titulação máxima; atuação como docente ou preceptor; e instituição de vinculação.

Parte II - Perguntas direcionadoras da produção do rol de competências em MLPM: 1) A formação médica no que diz respeito à medicina legal tem abrangência suficiente para as demandas da atuação médica hoje?; 2) O que o curso médico deve ensinar aos estudantes sobre medicina legal e perícias médicas para uma formação generalista?; 3) Quais conteúdos presentes hoje você não considera importantes para a formação?; 4) Quais práticas realizadas por um especialista em medicina legal e perícias médicas um estudante deve acompanhar durante sua formação?; 5) O que o médico generalista deve saber fazer com competência dentro do campo de medicina legal e perícias médicas após sua formação?

A Parte II foi desenvolvida a partir de questionamentos que remetem aos saberes relacionados a conhecimento, habilidades e atitudes em Medicina Legal e Perícias Médica baseadas no conteúdo do Libro Blanco (Peinado-Herreros, 2005). Nesse modelo as competências são divididas em duas seções: "saber" e "saber fazer". Entende-se por "saber" os conteúdos teóricos e conceituais relacionados ao conhecimento, como questionado nas perguntas 2 e 3 . No "saber-fazer" são trabalhadas habilidades e atitudes nas quais o aluno deve ser competente durante sua formação (perguntas 4 e 5). O "saber-fazer" engloba as práticas sob supervisão do tutor ou acompanhamento da prática de um especialista, bem como saber como fazer com competência (rotineiramente e sem supervisão).

Os resultados da primeira rodada foram sistematizados no Quadro 1, agrupando as competências em duas colunas: "saber" e "saber fazer".

Em um segundo momento, foi enviado outro questionário (Questionário 2) contendo o rol das competências observadas no primeiro momento acrescidas das competências não citadas pelos participantes mas consideradas importantes na formação médica segundo o Libro (Peinado-Herreros, 2005). As respostas visavam a confirmação dos resultados obtidos na primeira rodada. Nessa fase apenas oito especialistas responderam a pergunta "Você concorda que essas competências em medicina legal e perícias médicas correspondem às necessárias para formação de um médico generalista?" 
Essas novas respostas foram organizadas de acordo com o nível de concordância. Os 04 especialistas que não responderam a segunda etapa foram acionados novamente em três oportunidades, porém não prosseguiram com a pesquisa.

O nível de concordância (Cc) foi determinado utilizando o auxílio da seguinte formula estatística, sendo estabelecido como ponto de corte a concordância superior a 60\% (Santos, 2001): $\mathrm{Cc}=(1-\mathrm{Vn} / \mathrm{Vt}) *$ 100. Onde: $\mathrm{Cc}=$ coeficiente de concordância expresso em porcentagem; $\mathrm{Vn}$ = quantidade de especialistas em desacordo com o critério predominante; $\mathrm{e}$ $\mathrm{Vt}=$ quantidade total de especialistas.

As respostas referentes à segunda rodada foram agrupadas em colunas e correspondem à Tabela 1, que descreve as competências cognitivas relacionadas a "saber" e as habilidades e atitudes relacionadas a competência "saber fazer". A partir destes resultados foi construída uma Matriz de competências (Quadro 2). A matriz de competências em MLPM é o ponto de partida fundamental na discussão sobre a evolução da disciplina no processo de integração curricular e desenvolvimento do currículo médico.

A interpretação dos resultados esteve apoiada nos pressupostos da integração curricular conforme explicitado por Iglésias \& Bollela, 2015.

\section{RESULTADOS E DISCUSSÃO}

\subsection{Primeira Rodada}

A parte I do questionário determinou o perfil dos participantes. O gênero masculino foi preponderante com $58,3 \%$, estando, em sua maioria, acima dos 50 anos e com mais de 30 anos de formação.

Todos os 12 participantes eram docentes, sendo $25 \%$ deles mestres, $16,7 \%$ doutores e $16,7 \%$ pós doutores. Em relação à atuação acadêmica, o resultado foi equilibrado, apresentando seis entrevistados lecionando em instituições da rede pública e seis em instituições da rede privada de ensino.

Atualmente, cinco dos participantes trabalham em instituições de ensino de Alagoas e mais cinco trabalham noutras regiões do país, predominantemente na região Centro-Sul. Dessa forma amplia-se a relevância do debate a nível nacional. 
Em relação à área de atuação profissional, 66,7\% detinham o título de especialista em Medicina Legal e Perícias Médicas. Do total, $25 \%$ dos entrevistados atuam como médicos legistas, $25 \%$ como peritos médicos, 33,3\% como professores de Medicina Legal e 16,7\% são membros do Conselho Regional de Medicina. O equilíbrio entre legistas e peritos médicos pode possibilitar uma visão mais plural na construção da nova especialidade.

A parte II originou o rol de todas as competências em MLPM elencadas pelos participantes. À pergunta "a formação médica no que diz respeito à medicina legal tem abrangência suficiente para as demandas da atuação médica hoje?" os entrevistados, quase em totalidade, responderam "não". Um dos entrevistados ampliou essa compreensão enfatizando que "as Diretrizes Curriculares do Curso de Graduação em Medicina em uso não têm abrangência no ensino médico legal, suficiente para as demandas da atuação médica atual"1.

As respostas direcionadas à parte dois do questionário foram analisadas, listadas e divididas entre "saber" (conhecimento) e "saber-fazer" (habilidade), conforme demonstrado no Quadro 1.

Nota-se, dentre as respostas apresentadas, a introdução de conteúdos relacionados à perícia médica, a exemplo do conhecimento dos processos judiciais e suas particularidades, conhecimento do Código Civil, saber a diferença entre a Medicina Assistencial e a Pericial, dentre outras. Tais competências são imprescindíveis ao saber médico e ao caráter interdisciplinar que o currículo exige na atualidade. Outros sim, percebe-se raciocínio similar aplicado às habilidades, como a simulação do julgamento ético e o acompanhamento nos diversos tipos de perícias médicas.

A formação médica está em busca da integração curricular. É imprescindível articular as temáticas, uma vez que se deve levar em conta, na formação médica, o que de fato é significante no que tange a atuação prática profissional (Iglésias \& Bollela, 2015).

Segundo um dos entrevistados 2 :

A meu ver o curso de Medicina Legal deveria orientar os estudantes para que eles tivessem a capacidade de perceber e assim poder distinguir as situações de risco de pessoas no meio familiar, na comunidade, nas escolas, principalmente os mais

\footnotetext{
${ }^{1}$ Resposta encontrada no questionário de um dos entrevistados na primeira rodada.

${ }^{2}$ Resposta encontrada no questionário de um dos entrevistados na primeira rodada.
} 
indefesos como as crianças e idosos expostos às lesões corporais - principalmente de origem dolosa - praticadas por terceiros, sejam pessoas da família, parentes ou não, ou desconhecidos das vítimas. É muito comum encontrarmos em consultórios médicos, prontos-socorros ou em hospitais em geral, pessoas que sofrem agressões físicas ou psíquicas repetidas e não podem revelar ou se defender delas.

Passam despercebidas pelos médicos porque falta a eles a formação ideal para percebê-las. Quanto à perícia médica, os estudos deveriam ser embasados e fundamentados na relação causa e efeito das enfermidades agudas ou crônicas em relação a justiça criminal, cível, trabalhista e previdenciária.

Quadro 1. Rol de competências em medicina legal e perícias médicas necessárias para a formação do médico generalista elencadas por especialistas (elaborada pelos autores).

\section{Saber (conhecimento)}

Saber sobre a responsabilidade civil do profissional da saúde

Saber os direitos e deveres do profissional

Conhecer as implicações jurídicas do ato médico

Conhecer o código de ética médica

Ter conhecimento em ética

Ter conhecimento em bioética

Ter conhecimento de antropologia

Noções básicas de direito

Ser apresentado aos processos judiciais e suas

particularidades

Conhecer o código de processo civil

Saber a função do perito

Saber a diferença entre a medicina assistencial e pericial

Ter conhecimentos em agentes vulnerantes e suas

lesões

Conhecimentos em documentos médicos

Noções de necropsia

Noções de tanatologia

Noções de psicopatologia

Legislação sobre lesões corporais

Noções de sexologia

Conhecer a medicina do trabalho

Conhecer as normas regulamentadoras do Ministério do

Trabalho

Distinção de situações de risco de pacientes em

vulnerabilidade social

Diagnóstico de morte

Preenchimento de atestado de óbito

Proceder perícia médica

\author{
Saber Fazer (habilidade) \\ Elaborar e interpretar um laudo \\ médico \\ Diagnóstico de morte \\ Preenchimento de atestado de \\ óbito \\ Adequado encaminhamento do \\ óbito aos serviços competentes \\ Acompanhar a realização de um \\ exame cautelar \\ Abordagem adequada à vítima de \\ abuso sexual \\ Acompanhar a realização de um \\ exame de conjunção carnal \\ Simulação de julgamento ético \\ Proceder perícia médica \\ Acompanhar uma perícia \\ previdenciária \\ Acompanhar uma perícia judicial \\ Acompanhar uma perícia \\ trabalhista \\ Acompanhar uma perícia cível \\ Acompanhar uma perícia criminal
}

A ideia de um currículo baseado em competências parte do pressuposto de que, para o desenvolvimento do médico, torna-se imprescindível a integração de conhecimento técnico- 
científico, habilidades, atitudes, valores éticos à personalidade do indivíduo (Santos, 2001).

Um currículo deve deixar evidentes as competências que se almeja, em forma de objetivos de aprendizagem específicos vinculados a um projeto que demonstre a forma que esse objetivo será vencido e de que maneira ele será avaliado (Bollela, Lúcio, \& Machado, 2010).

As Novas Diretrizes Curriculares Nacionais do Curso de Graduação em Medicina, definem, claramente, os elementos para a formação do perfil do médico:

O graduado em Medicina terá formação geral, humanista, crítica, reflexiva e ética, com capacidade para atuar nos diferentes níveis de atenção à saúde, com ações de promoção, prevenção, recuperação e reabilitação da saúde, nos âmbitos individual e coletivo, com responsabilidade social e compromisso com a defesa da cidadania, da dignidade humana, da saúde integral do ser humano e tendo como transversalidade em sua prática, sempre, a determinação social do processo de saúde e doença (Resolução $n^{\circ}$ 3, 2014).

Ao construir o seu currículo, cada instituição de ensino superior deve deixar claro o perfil do médico que pretende formar, podendo, ainda, flexibilizar a fim de adaptar às suas necessidades sociais regionais.

Ao definir esse perfil, formaliza-se um compromisso com os resultados que se pretende alcançar. Deve-se sempre fixar quais as capacidades e resultados esperados do estudante de Medicina ao final do curso, assim como em cada disciplina (Bollela et al., 2010).

\subsection{A Segunda Rodada}

As respostas à segunda rodada da pesquisa (lista das respostas obtidas na primeira etapa, acrescidas das competências elencadas no Libro Blanco e que não foram citadas por nenhum dos entrevistados) são demonstradas no Tabela 1.

Todas as competências em MLPM estão listadas conforme o coeficiente de concordância. 
Tabela 1. Nível de concordância dos temas relacionados a conhecimentos e habilidades em Medicina Legal e Perícias Médicas para compor a matriz de competências (elaborada pelos autores).

\begin{tabular}{|c|c|c|}
\hline Saber (conhecimento) & Saber Fazer (habilidade) & $\begin{array}{c}\text { Nível de } \\
\text { Concordância }\end{array}$ \\
\hline $\begin{array}{l}\text { Principais documentos médico- } \\
\text { legais. } \\
\text { Noções de tanatologia. } \\
\text { Implicações sociais e legais dos } \\
\text { fenômenos da morte. } \\
\text { O transplante de órgãos. } \\
\text { Legislação sobre lesões corporais. } \\
\text { Noções de sexologia forense. }\end{array}$ & $\begin{array}{l}\text { Redigir corretamente documentos médico- } \\
\text { legais. } \\
\text { Atenção à uma vítima de violência em meio } \\
\text { doméstico. }\end{array}$ & $100 \%$ \\
\hline $\begin{array}{l}\text { Os valores profissionais (excelência, } \\
\text { altruísmo, sentido de dever, } \\
\text { responsabilidade, integridade e } \\
\text { honestidade). } \\
\text { Implicações jurídicas do ato médico. } \\
\text { O código de ética médica. } \\
\text { A função do perito. } \\
\text { Noções de necropsia. } \\
\text { Psiquiatria forense. } \\
\text { O mecanismo básico de ação das } \\
\text { substâncias tóxicas. } \\
\text { Principais agentes causadores de } \\
\text { intoxicação. } \\
\text { Drogas. }\end{array}$ & $\begin{array}{l}\text { Elaborar e interpretar um laudo médico. } \\
\text { Diagnóstico de morte. } \\
\text { Preenchimento de atestado de óbito. } \\
\text { Abordagem adequada à vítima de abuso } \\
\text { sexual. }\end{array}$ & $87,5 \%$ \\
\hline $\begin{array}{l}\text { Direitos e deveres do profissional. } \\
\text { A diferença entre a medicina } \\
\text { assistencial e pericial. } \\
\text { A perícia profissional. Causas e } \\
\text { semiologias das lesões. } \\
\text { Conservação do cadáver. } \\
\text { Genética forense. } \\
\text { A violência familiar, violência de } \\
\text { gênero, violência contra as crianças } \\
\text { e contra os idosos. }\end{array}$ & $\begin{array}{l}\text { Ler a legislação e interpretá-la. } \\
\text { Participar de simulação de julgamento ético. } \\
\text { Adequado encaminhamento do óbito aos } \\
\text { serviços. } \\
\text { Observar a realização de uma autópsia } \\
\text { judicial. } \\
\text { Diagnóstico clínico e laboratorial no caso de } \\
\text { impregnações devido a substâncias tóxicas } \\
\text { comuns no nosso local de trabalho. }\end{array}$ & $75 \%$ \\
\hline $\begin{array}{l}\text { Conhecimentos em ética. } \\
\text { Conhecimentos em bioética. } \\
\text { Os processos judiciais e suas } \\
\text { particularidades. } \\
\text { O código de processo civil. } \\
\text { A medicina do trabalho. } \\
\text { Conhecimentos elementares de } \\
\text { criminalística, do exame do local de } \\
\text { crime, dos principais indícios, sua } \\
\text { preparação, coleta e transporte. } \\
\text { Atuação médico legal em grandes } \\
\text { catástrofes. } \\
\text { Antropologia forense. }\end{array}$ & $\begin{array}{l}\text { Proceder perícia médica. } \\
\text { Acompanhar uma perícia criminal. } \\
\text { Acompanhar uma perícia previdenciária. } \\
\text { Acompanhar a aplicação de medidas } \\
\text { elementares de prevenção de acidentes de } \\
\text { trabalho e doenças ocupacionais. } \\
\text { Acompanhar uma perícia cível. } \\
\text { Coletar amostras de um cadáver e prepará- } \\
\text { las. } \\
\text { Acompanhar a realização de um exame } \\
\text { cautelar. } \\
\text { Acompanhar a realização de um exame de } \\
\text { conjunção carnal. } \\
\text { Observar a elaboração de uma ficha } \\
\text { datilográfica e odontológica para identificação } \\
\text { de cadáveres. }\end{array}$ & $62,5 \%$ \\
\hline Noções básicas de direito. & $\begin{array}{l}\text { Acompanhar uma perícia trabalhista. } \\
\text { Acompanhar uma perícia de valoração de } \\
\text { danos pessoais. } \\
\text { Observar a realização de exame básico de } \\
\text { uma paciente suspeita de um aborto criminal. }\end{array}$ & $50 \%$ \\
\hline Ecotoxicologia. & & $37,5 \%$ \\
\hline
\end{tabular}


O ponto de corte utilizado, segundo (Santos, 2001), é representado empiricamente pelo nível de concordância acima de $60 \%$. Esse parâmetro é relevante para a produção da matriz curricular.

Lançando mão desse critério, observa-se que temas de relevante impacto na coletividade foram menosprezados. Fica claro que a formação médica e as questões éticas valorizam mais a relação médico-paciente, isolando o profissional médico da formação multiprofissional e da responsabilidade social. A busca de estratégias de aproximação da escola ao Sistema Único de Saúde tem como direcionamento a necessidade de formação médica com responsabilidade social (Iglésias \& Bollela, 2015).

Este resultado reflete o atual estágio da ética médica direcionada para as questões éticas da relação médico-paciente em detrimento das questões coletivas (Soares, Shimizu \& Garrafa, 2017). Dentre as competências gerais presentes nas DCNs de 2014, em relação à atenção à saúde, há um direcionamento claro no qual o estudante de Medicina deve se perceber enquanto peça fundamental para a construção de uma sociedade mais comprometida com o coletivo, sem se restringir profissionalmente ao atendimento médico individual e tecnicista, como pôs a Resolução nº 3 (2014) do Conselho Nacional de Educação.

A ecotoxicologia, com apenas $37,5 \%$ de concordância, foi excluída da matriz. Contudo, seu debate tem extrema relevância hoje, uma vez que a utilização de agrotóxicos e alimentos geneticamente modificados é cada vez mais discutida no nosso cotidiano. É o conhecimento legal de temas em saúde coletiva que promove uma aproximação da Medicina com as políticas públicas a serem desenvolvidas. Critica-se aqui o uso do método como indutor de viés de seleção, devendo-se estabelecer a aleatoriedade de apresentação temática aos participantes nas distintas fases da pesquisa.

A habilidade de observar a realização de exame básico de uma paciente suspeita de um aborto criminal é outro tema de relevante impacto social inserido na discussão através das competências observadas no Libro Blanco (Peinado-Herreros, 2005) e que foi retirado da matriz por não chegar ao nível de concordância estabelecido, evidenciando o desinteresse médico. A descriminalização do aborto é um tema polêmico e atual. Há um grave desconhecimento dos estudantes e médicos em relação às recomendações éticas na condução dos casos em que o aborto é permitido (Fonseca, Domingues, Leal, Aquino \& Menezes, 2020). 
Considerando o critério adotado para ponto de corte, foi elaborada matriz de competências em Medicina Legal e Perícias Médicas (Quadro 2) no intuito de contribuir para o desenvolvimento curricular do curso de Medicina.

\subsection{A Matriz de Competências em Medicina Legal e Perícias Médicas}

Quadro 2. Matriz sugerida de competências em Medicina Legal e Perícias Médicas (elaborada pelos autores).

\begin{tabular}{|c|c|}
\hline Saber (conhecimento) & Saber Fazer (habilidade) \\
\hline $\begin{array}{l}\text { Aspectos deontológicos e diceológicos } \\
\text { Direitos e deveres do profissional } \\
\text { Implicações jurídicas do ato médico } \\
\text { O código de ética médica } \\
\text { Conhecimentos em ética e bioética } \\
\text { Os processos judiciais e suas } \\
\text { particularidades } \\
\text { O código de processo civil } \\
\text { A função do perito } \\
\text { A diferença entre a medicina assistencial e } \\
\text { pericial } \\
\text { A perícia profissional. Causas e } \\
\text { semiologias das lesões. } \\
\text { Principais documentos médico-legais } \\
\text { Noções de tanatologia } \\
\text { Implicações sociais e legais dos fenômenos } \\
\text { da morte. O transplante de órgãos } \\
\text { Noções de necropsia } \\
\text { Conservação do cadáver } \\
\text { Psiquiatria forense } \\
\text { Legislação sobre lesões corporais } \\
\text { Noções de sexologia forense } \\
\text { A medicina do trabalho } \\
\text { Conhecimentos elementares de } \\
\text { criminalística, do exame do local de crime, } \\
\text { dos principais indícios, sua preparação, } \\
\text { coleta e transporte. } \\
\text { Genética forense } \\
\text { Atuação médico legal em grandes } \\
\text { catástrofes } \\
\text { A violência familiar, violência de gênero, } \\
\text { violência contra as crianças e contra os } \\
\text { idosos } \\
\text { O mecanismo básico de ação das } \\
\text { substâncias tóxicas. Principais agentes } \\
\text { causadores de intoxicação. } \\
\text { Drogas. Antropologia forense }\end{array}$ & $\begin{array}{l}\text { Ler a legislação e interpretá-la } \\
\text { Participar de simulação de julgamento ético } \\
\text { Proceder perícia médica } \\
\text { Acompanhar perícias criminal, cível e } \\
\text { previdenciária } \\
\text { Acompanhar a aplicação de medidas } \\
\text { elementares de prevenção de acidentes de } \\
\text { trabalho e doenças ocupacionais } \\
\text { Elaborar e interpretar documentos médico- } \\
\text { legais } \\
\text { Diagnóstico de morte } \\
\text { Preenchimento de atestado de óbito } \\
\text { Adequado encaminhamento do óbito aos } \\
\text { serviços competentes } \\
\text { Coletar amostras de um cadáver e prepará-las } \\
\text { Observar a realização de uma autópsia judicial } \\
\text { regulamentada } \\
\text { Acompanhar a realização de um exame } \\
\text { cautelar } \\
\text { Abordagem adequada à vítima de abuso } \\
\text { sexual } \\
\text { Acompanhar a realização de um exame de } \\
\text { conjunção carnal } \\
\text { Atenção à uma vítima de violência em meio } \\
\text { doméstico } \\
\text { Diagnóstico clínico e laboratorial no caso de } \\
\text { impregnações devido a substâncias tóxicas } \\
\text { comuns no nosso local de trabalho } \\
\text { Observar a elaboração de uma ficha } \\
\text { datilográfica e odontológica para identificação } \\
\text { de cadáveres }\end{array}$ \\
\hline
\end{tabular}

Em 2009 os Ministérios da Saúde e Educação lançaram a Matriz de Correspondência Curricular para Fins de Revalidação de Diplomas de Médico Obtidos no Exterior de acordo com as Diretrizes Curriculares Nacionais dos Cursos de Graduação em Medicina. Esta é baseada na aquisição de competências e composta por conteúdos mais relevantes, 
habilidades e atitudes básicas ao exercício profissional. Dentre as habilidades específicas em Medicina Legal, observa-se que o médico deve realizar de maneira autônoma: o preenchimento e atualização de prontuário; prescrição em receituário comum; prescrição em receituário controlado; diagnóstico de óbito e preenchimento de atestado; solicitação de autópsia; emissão de outros atestados; emissão de relatórios médicos; e a obtenção de consentimento informado nas situações requeridas, conforme Portaria Interministerial $n^{\circ} 865$ (2009).

A matriz de competências direciona para as estratégias educacionais que podem ser utilizadas na formação médica e, simultaneamente, serve como método de desenvolvimento curricular para atingir as demandas sociais atuais.

A integração curricular tem um papel fundamental na consolidação do perfil do egresso. A organização de uma matriz curricular deve seguir nesse caminho facilitador da aprendizagem.

É possível notar na Matriz de Competências em Medicina Legal e Perícias Médicas (Quadro 3) algumas competências que denotam um processo inicial de transformação no pensamento do profissional em MLPM. A seleção de temas como abordagem à vítima de violência sexual e atenção à vítima de violência em meio doméstico indicam preocupação e aproximação da atuação do médico com as questões sociais.

A atualização e efetivação dessas competências elencadas no estudo devem ser estimuladas, reconhecendo-se o caráter transversal e a exigência da interdisciplinaridade e das metodologias ativas como estratégias políticas educacionais para a definição de perfil adequado do egresso médico.

Habilidades como participar de simulação de julgamento ético, redigir corretamente documentos médicos legais e elaborar e interpretar laudos demonstram com clareza essa exigência.

\section{CONCLUSÕES}

As perícias médicas têm, no mundo de hoje, papel fundamental na formação e no cotidiano do trabalho em saúde. A vulnerabilidade social e as necessidades de garantia de direitos põem a urgência de indivíduos éticos capazes de mediar conflitos e contribuir para a pacificação social. 
Em que pese o presente estudo ter sido originado a partir da necessidade de reformulação da matriz curricular de um curso, a demanda é comum às demais instituições de ensino. Ao permitir a participação de especialistas, em busca de consenso, o método adotado (Delphi) propiciou a reflexão e a contribuição de profissionais em contextos distintos: público e privado, homens e mulheres, tempo de formação diferenciado, docentes e não docentes, locais e de outros estados. Os resultados apontam para a influência dominante na formação de uma Medicina Legal tradicional; porém, estes devem ser novamente contextualizados para reflexão em cada curso, com a intenção de inclusão de temas atuais e mais vinculados ao campo pericial. O método Delphi oferece a possibilidade de contribuir para o ensino em saúde agregando opiniões convergentes e divergentes para reflexão, compreensão, e composição temática específica a determinada área do conhecimento. Cabe observar como limitação do método um possível viés de seleção, o qual sugerimos superar com apresentação aleatória do conteúdo temático aos participantes das pesquisas. O ponto de corte para definição temática é outro aspecto a ser considerado de forma crítica pelos pesquisadores. No entanto, com a seleção do tema como objeto de estudo, e os resultados apresentados, é proposta a modificação sistemática na disciplina de MLPM e na discussão acerca da importância do campo pericial, integrando-o à uma matriz curricular inovadora e que busca contribuir com a humanização da formação médica.

\section{REFERÊNCIAS}

Biernacki, P., \& Waldorf, D. (1981). Snowball sampling: Problems and techniques of chain referral sampling. Sociological Methods \& Research, 10(2), 141-163.

Bollela, V. R., Lúcio, J., \& Machado, M. (2010). Internato baseado em competências: "Bridging the gaps". Belo Horizonte, Brasil: Medvance.

Constituição da República Federativa do Brasil (1988). Brasília, Brasil: Senado Federal.

França, G. V. (2015). Medicina legal. (10ª ed.). Rio de Janeiro, Brasil: Guanabara Koogan.

Fonseca, S. C., Domingues, R. M. S. M., Leal, M. C., Aquino, E. M. L., \& Menezes, G. M. S. (2020). Aborto legal no Brasil: Revisão sistemática da produção científica, 2008-2018. Cadernos de saúde pública, 36(1), 1-27. doi: 10.1590/0102-311X00189718

Gontijo, E. D., Alvim, C., Megale, L., Melo, J. R. C., \& Lima, M. E. C. C. (2013). Matriz de competências essenciais para a formação e avaliação de desempenho de estudantes de medicina. Revista Brasileira de Educação Médica, 37(4), 526-539. doi: 10.1590/S0100-55022013000400008

Iglésias, A. G., \& Bollela, V. R. (2015). Integração curricular: Um desafio para os cursos de graduação da área da Saúde. Medicina, 48(3), 265-272.

Peinado-Herreros, J. (Coord.). (2005). Libro blanco: título de grado en Medicina. Granada, España: Agencia Nacional de Evaluación de la Calidad y Acreditación. 
Portaria interministerial $n^{\circ}$ 865. (2009, Setembro). In Matriz de correspondência curricular para fins de revalidação de diplomas de médico obtidos no exterior (pp. 11-13). Brasilia, Brasil: Ministério da Educação.

Resolução CFM nº 1.973 (2011, Agosto). Diário Oficial da União nº 146, Brasília: Presidência da República.

Resolução $n^{\circ}$ 3. (2014, Junho). Institui diretrizes curriculares nacionais do curso de graduação em Medicina e dá outras providências.

Sáfadi, C. M. Q. (2001). Delphi: Um estudo sobre sua aceitação. V seminário em administração FEA-USP, 1-14. São Paulo, Brasil: Universidade de São Paulo.

Santos, A. C. (2001). O uso do método Delphi na criação de um modelo de competências. Revista de Administração, 36(2), 25-32.

Scarparo, A. F., Laus, A. M., Lidia, C., Gabriel, C. S., Dias, L., \& Chaves, P. (2012). Reflexões sobre o uso da técnica Delphi em pesquisas na enfermagem. Revista da Rede de Enfermagem do Nordeste, 13(1), 242251.

Soares, F. J. P., Shimizu, H.E., \& Garrafa, V. (2017). Código de ética médica brasileiro: limites deontológicos e bioéticos. Revista Bioética, 25(2), 244-54. doi: 10.1590/1983-80422017252184

Villiers, M. R., Villiers, P. J. T., \& Kent, A. P. (2005). The Delphi technique in health sciences education research. Medical Teacher, 27(7), 639-643. doi: 10.1080/13611260500069947 